\title{
Concentrado protéico de soro como substituto de gordura em pão de queijo
}

\author{
Whey protein concentrate as a fat substitute in cheese bread
}

\section{Autores | Authors}

Francy ZAMBRANO

Doutora em Tecnologia de Alimentos e-mail: francyzambrano@hotmail.com

Marina Costa da SILVA

Universidade Estadual de Campinas (UNICAMP) Faculdade de Engenharia de Alimentos (FEA)

Campinas/SP - Brasil

e-mail:marinacs@fea.unicamp.br

凶 Rita de Cássia Celeste ORMENESE

Instituto de Tecnologia de Alimentos (ITAL) Centro de Ciência e Qualidade de Alimentos (CCQA)

Av. Brasil, 2.880

CEP: $13070-178$

Campinas/SP - Brasil

e-mail: ritaorm@ital.sp.gov.br

Katumy YOTSUYANAGI

Instituto de Tecnologia de Alimentos (ITAL) Centro de Ciência e Qualidade de Alimentos (CCQA) Campinas/SP - Brasil e-mail: katumyot@ital.sp.gov.br

\. Autor Correspondente / Corresponding Author

Recebido / Received: 30/08/2010 Aprovado / Approved: 13/06/2012 Publicado / Published: set./2012

\section{Resumo}

O objetivo deste trabalho foi avaliar o efeito da adição de concentrado proteico de soro (CPS) como substituto de gordura, além de determinar os melhores níveis de adição em pão de queijo elaborado por meio de dois processos de fabricação e comparar o efeito da substituição durante a estocagem. O efeito da substituição foi avaliado sensorialmente por meio de aparência, aparência da casca, textura e sabor e pela avaliação geral por uma equipe de cinco especialistas em tecnologia de pão de queijo, selecionados quanto à acuidade sensorial. Também foram determinados a textura em texturômetro TA-XT2i e o volume específico pelo método de deslocamento de sementes. A análise estatística dos resultados foi realizada por meio da análise de variância (ANOVA) e do teste de Tukey no nível de 5\% de significância, utilizando-se o programa estatístico SAS (Statistical Analysis System, versão 8.0 - The SAS Institute, Cary, N.C.). As características sensoriais do pão de queijo escaldado (PQE) e do pão de queijo sem escaldamento (PQSE) estocados por até três meses não apresentaram diferença significativa $(p>0,05)$ em relação a cada padrão, quando a gordura foi substituída em níveis de 50 e 100\%, respectivamente. O pão de queijo sem escaldamento (PQSE) com $50 \%$ de substituição de gordura, estocado durante quatro meses, apresentou diferença significativa $(p<0,05)$ apenas na textura e na aparência da casca. Das características avaliadas no pão de queijo escaldado (PQE) e no pão de queijo sem escaldamento (PQSE) com substituição de gordura, a que apresentou maiores diferenças significativas $(p<0,05)$ foi a textura instrumental. Os melhores níveis de substituição foram $50 \%$ e $100 \%$ de gordura no pão de queijo escaldado (PQE) e no pão de queijo sem escaldamento (PQSE), respectivamente.

Palavras-chave: Concentrado proteico de soro; Substitutos de gordura; Panificação.

\section{Summary}

The objective of this research was to evaluate the effect of substituting the fat by whey protein concentrate (WPC) in scalded (SCB) and non-scalded (NSCB) cheese bread, determine the best levels of addition and compare the effect of substitution during storage. The sensory characteristics of sample appearance, crust appearance, texture and flavor were evaluated by a team of 5 judges selected on the basis of their sensory acuity and with experience in cheese bread technology. The specific volume was also determined using the seed displacement method, and the texture using the TA-XT2i texturometer. The results were evaluated by the analysis of variance (ANOVA) and Tukey's test at the 5\% significance level, using the Statistical Analysis System, version 8.0 (The SAS Institute, Cary, N.C., USA). For SCB and NSCB and 3 months of storage, the substitution of fat up to levels of $50 \%$ and $100 \%$, respectively, caused no significant differences $(p>0.05)$ when compared with the standard. The NSCB with $50 \%$ fat substitution and 4 months of storage only showed a significant difference $(p<0.05)$ for texture and crust appearance. Of the characteristics evaluated in the scalded (SCB) and non-scalded (NSCB) cheese bread with fat substitution, that showing the greatest significant $(p<0.05)$ differences was instrumental texture. The best substitution levels were $50 \%$ fat in the scalded cheese bread and $100 \%$ fat in the non-scalded cheese bread.

Key words: Whey protein concentrate; Fat substitute; Breadmaking. 


\section{Introdução}

O pão de queijo é um produto tradicionalmente do Estado de Minas Gerais, hoje largamente consumido no Brasil e que está ganhando o mercado internacional, graças à possibilidade de congelamento da massa e à grande comercialização de misturas prontas (PEREIRA et al., 2004).

Não existe Padrão de Identidade e Qualidade de pão de queijo que defina requisitos de qualidade do produto. Sob a denominação de 'pão de queijo', podem ser encontrados no mercado diferentes tipos de produtos (SANTOS, 2006).

A grande maioria dos produtores de pão de queijo utiliza o método de fabricação tradicional, que consiste em escaldar a fécula e/ou o polvilho com o óleo, a água e/ou o leite. A seguir, é realizado amassamento com os ovos, adição do queijo e assamento (PIROZI e CANAVESI, 1998). Também é possível elaborar pão de queijo sem realizar a etapa de escaldamento com a utilização de amido modificado.

Enquanto na elaboração de pão de queijo sem escaldamento (PQSE), o amido modificado desempenha uma importante função, no processamento do pão de queijo escaldado (PQE), o escaldamento é considerado uma etapa muito importante por afetar a textura, o sabor e a aparência final do produto. Nessa etapa, ocorrem modificações na estrutura interna do grânulo de amido por causa do calor e da água. O aquecimento provoca a quebra das pontes de hidrogênio que mantêm o seu arranjo molecular e, com isso, ocorre o fenômeno de hidratação e inchamento dos grânulos, conhecido como gelatinização (PEREIRA, 1998). A temperatura necessária para a gelatinização dos grânulos do amido de mandioca é de 58 a $70{ }^{\circ} \mathrm{C}$. Durante o assamento do pão de queijo, nos primeiros minutos, quando a temperatura atinge aproximadamente $55^{\circ} \mathrm{C}$, o amido começa a gelatinizar. Posteriormente, em valores próximos a $77^{\circ} \mathrm{C}$, os grânulos de amido aumentam de tamanho e são fixados na estrutura proteica (PEREIRA, 1998).

O pão de queijo apresenta maior valor calórico quando comparado com outros produtos, sendo que cada unidade de $24 \mathrm{~g}$ contém aproximadamente $85 \mathrm{Kcal}$ (CLARETO et al., 2006). A substituição de gorduras por ingredientes que apresentem características físicoquímicas semelhantes às gorduras, porém com menos calorias, é uma das propostas sugeridas para diminuir o consumo de gorduras (PASCAL, 1992) e calorias, uma vez que a gordura ( $\left.9 \mathrm{Kcal} . \mathrm{g}^{-1}\right)$ é uma fonte concentrada de energia.

O consumo excessivo de gorduras tem sido relacionado com o aumento de doenças, como hipertensão arterial - a chamada pressão alta -, diabetes melito, doenças cardiovasculares e outras associadas à obesidade (PASCAL, 1992).

A produção mundial de soro de queijo é de aproximadamente 120 milhões de toneladas anuais e gera 720 mil toneladas de proteínas (GIRALDO-ZUNIGA et al., 2002). Uma parcela considerável dessa produção é descartada em rios, provocando assim problemas ambientais em razão da sua alta demanda bioquímica de oxigênio (DBO) (CONDACK, 1992).

O descarte do soro é um desperdício de material proteico e de outros nutrientes (ALMEIDA et al., 2001). O Índice de Eficiência Proteica (PER) e o Valor Biológico (VB) dessas proteínas superam os obtidos pelas caseínas (ANTUNES et al., 2004). Além disso, as proteínas do soro apresentam propriedades bioativas (ANTUNES et al., 2004; PACHECO et al., 2005).

Uma forma de aumentar o reaproveitamento do soro produzido no Brasil (15\%) (NEVES, 2001) é diversificar a utilização do soro na forma de CPS (Concentrados Proteicos de Soro), utilizados mundialmente como ingrediente em alimentos.

Alguns estudos avaliaram os CPS Simplesse e/ou Dairy-Lo em iogurte (McMAHON et al., 1996; YAZICI e AKGUN, 2004; ANTUNES et al., 2004); queijos (SANDOVAL-CASTILLA et al., 2004); bebidas lácteas (SIVIERI e OLIVEIRA, 2002), e produtos de panificação (O'BRIEN et al., 2003; BENASSI et al., 2001; ESTELLER e LANNES, 2005; CLARETO et al., 2006). Os últimos autores avaliaram a substituição de gordura em pão de queijo produzido pelo método tradicional de escaldamento utilizando Dairy-Lo. No entanto, não foi comparado o efeito da substituição de gordura nos dois processos de fabricação estudados.

O objetivo deste trabalho foi avaliar o efeito da adição de CPS como substituto de gordura em pão de queijo escaldado (PQE) e sem escaldamento (PQSE), bem como determinar quais os melhores níveis de adição e comparar o efeito da substituição nos dois processos de fabricação durante a estocagem.

\section{Material e métodos}

Este trabalho foi realizado no Centro de Tecnologia de Cereais e Chocolates do Instituto de Tecnologia de Alimentos, Campinas-SP.

\subsection{Materiais}

As matérias-primas utilizadas foram fécula de mandioca (Pinduca), polvilho azedo (Pinduca), amido de mandioca modificado National 75 (National Starch) e o concentrado proteico de soro (CPS) Dairy-Lo (CultorDanisco, São Paulo, Brasil). Foram também utilizados queijo tipo minas padrão, leite integral, ovos in natura, óleo e sal, sendo todos comprados no mercado local. 
Os equipamentos utilizados no processo de fabricação de pão de queijo foram: batedeira planetária (Kitchen AID, modelo e série: K5SS); multiprocessador (Braun do Brasil tipo: MC-1); forno elétrico Modelo Layr (J. Ryal \& Cia); balança semianalítica; freezer horizontal (Metalfrio) e analisador de textura (Stable Micro Systems, TA-XT2i).

\subsection{Métodos}

Os testes de substituição de gordura em pão de queijo foram realizados com base nos resultados de avaliação preliminar (ZAMBRANO et al., 2009), utilizando-se dois processos de fabricação. No primeiro processo, foi realizado escaldamento da fécula de mandioca e do polvilho azedo com uma mistura de óleo e água/leite fervente. No segundo, não foi utilizado escaldamento, a mistura dos ingredientes foi realizada a frio e foi utilizado o amido modificado National Starch.

\subsubsection{Formulação do pão de queijo escaldado (PQE) e pão de queijo sem escaldamento (PQSE)}

A Tabela 1 apresenta as duas formulações de PQE e PQSE (ZAMBRANO et al., 2009), utilizadas como padrão para avaliar o efeito da substituição de gordura nas características sensoriais, na textura instrumental e no volume específico.

As Tabelas 2 e 3 apresentam as modificações dos ingredientes nos testes de substituição no PQE e PQSE, respectivamente. As porcentagens de acréscimo (+) ou diminuição (-) são expressas em relação a cada uma das formulações padrão apresentadas na Tabela 1. Nas Tabelas 2 e 3, constam apenas os ingredientes que foram alterados.

\subsubsection{Modo de preparo}

\section{Pão de queijo escaldado (PQE)}

Para o preparo do PQE, os ingredientes secos (fécula e polvilho) foram homogeneizados durante três minutos. A seguir, o óleo, a água e o leite foram aquecidos até temperatura de ebulição e mantidos nessa temperatura durante dois minutos. A mistura de óleo, água e leite quente foi adicionada sobre a fécula e o polvilho previamente homogeneizados, sendo misturados durante um minuto. Na sequência, o sal previamente dissolvido no ovo e o queijo foram adicionados e misturados durante três minutos. No preparo do PQE, a mistura foi realizada na velocidade baixa.

\section{Pão de queijo sem escaldamento (PQSE)}

Durante o preparo do PQSE, os ingredientes secos (fécula de mandioca, amido modificado e leite em pó) foram misturados por cinco minutos na velocidade mais baixa do equipamento. A seguir, foi adicionada e misturada a gordura vegetal hidrogenada, na mesma velocidade, durante cinco minutos. Na sequência, foi incorporado o sal previamente dissolvido no ovo, sendo misturado na velocidade 2 durante um minuto. O queijo previamente ralado foi adicionado e misturado por um minuto; e, finalmente, misturou-se a água, por mais cinco minutos, na mesma velocidade.

Nos testes de substituição de gordura nas formulações de PQE e PQSE, o CPS foi misturado junto com os ingredientes secos. Conforme orientação dos fabricantes e resultados da avaliação preliminar (ZAMBRANO et al., 2009), a substituição foi realizada na proporção de 3:1 (gordura:CPS).

Tabela 1. Formulações padrão de PQE e PQSE.

\begin{tabular}{lcc}
\multicolumn{1}{c}{ Ingrediente } & PQE & (\%) \\
\hline Fécula de mandioca & 34,00 & 28,31 \\
Polvilho & 4,73 & - \\
Amido modificado National 75 & - & 8,82 \\
Queijo minas padrão & 16,93 & 22,1 \\
Ovo integral & 9,00 & 17,17 \\
Óleo & 9,5 & - \\
Gordura vegetal hidrogenada & - & 6,33 \\
Água & 15,44 & 13,93 \\
Leite líquido integral & 9,00 & - \\
Leite em pó desnatado & - & 2,0 \\
Sal & 1,4 & 1,34 \\
Total & 100 & 100 \\
\hline
\end{tabular}

Tabela 2. Adaptações da formulação do PQE com substituição de gordura.

\begin{tabular}{lccc}
\multicolumn{1}{c}{ Ingrediente } & \multicolumn{3}{c}{ Nível de substituição $^{\prime}$} \\
& $\mathbf{2 5}$ & $\mathbf{5 0}$ & $\mathbf{7 5}$ \\
\hline Ovo integral & -17 & -28 & +61 \\
Óleo vegetal & -25 & -50 & -75 \\
Água* $^{*}$ & +15 & +31 & +46 \\
CPS ** $^{*}$ & +8 & +17 & +25 \\
\hline
\end{tabular}

${ }^{*}$ A porcentagem de acréscimo (+) ou diminuição (-) é expressa em

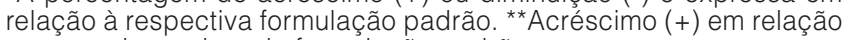
ao peso de gordura da formulação padrão.

Tabela 3. Adaptações da formulação do PQSE com substituição de gordura.

\begin{tabular}{lcccc} 
& \multicolumn{4}{c}{ Nível de substituição } \\
Ingrediente & $\mathbf{2 5}$ & $\mathbf{5 0}$ & $\mathbf{7 5}$ & $\mathbf{1 0 0}$ \\
\hline Gordura vegetal hidrogenada & -25 & -50 & -75 & -100 \\
Água* & & & -5 & -5 \\
Sal & & & & -10 \\
CPS $^{* *}$ & +8 & +17 & +25 & +33 \\
\hline
\end{tabular}

*A porcentagem de acréscimo (+) ou diminuição (-) é expressa em relação à respectiva formulação padrão. **Acréscimo $(+)$ em relação ao peso de gordura da formulação padrão. 
As amostras de PQE e PQSE foram moldadas e pesadas (25 a $26 \mathrm{~g}$ ) manualmente. O assamento de PQE e PQSE foi realizado com controle de temperatura de $170{ }^{\circ} \mathrm{C}$ a $190^{\circ} \mathrm{C}$ durante $29 \mathrm{~min}$. Nos primeiros $15 \mathrm{~min}$, a chave superior do forno permaneceu desligada e a chave inferior, ligada no nível médio; nos últimos 14 min, as duas chaves permaneceram ligadas nesse nível.

\subsubsection{Avaliação do pão de queijo}

Todas as amostras de PQE e PQSE foram analisadas quanto as características sensoriais, volume específico e textura. As amostras de PQE e PQSE foram avaliadas durante 4 e 5 períodos, respectivamente. Os períodos 0, 1, 2, 3 e 4 foram considerados 1, 30, 60, 90 e 120 dias, respectivamente, após a elaboração das amostras.

As amostras de PQE foram analisadas por três meses e as de PQSE, durante quatro meses de estocagem.

Todas as amostras de PQE e PQSE foram congeladas, embaladas em polietileno de baixa densidade e estocadas em freezer horizontal a $-15^{\circ} \mathrm{C}$, inclusive aquelas avaliadas no período zero (um dia de estocagem).

\section{Análise sensorial}

As características sensoriais de aparência, aparência da casca, textura e sabor das amostras foram avaliadas por uma equipe composta por cinco especialistas em tecnologia de fabricação de pão de queijo e técnicos da área com grande conhecimento acerca das características adequadas para um pão de queijo de qualidade. Além disso, os cinco provadores foram selecionados quanto à acuidade sensorial, de acordo com a norma ISO-8586-1 (ISO, 1993). Essa equipe definiu, em conjunto, os atributos que deveriam ser avaliados, as escalas empregadas para cada atributo com termos característicos de pão de queijo de baixa e de elevada qualidade. Tal definição permitiu ainda avaliar cada amostra de forma global, levando em consideração o quanto cada uma delas se aproximava ou não de um produto completamente característico.

Foi empregada uma escala estruturada em que os pontos 1 e 5 foram definidos conforme descrito a seguir: aparência (1. nota mínima - pouco atraente: falta de cor, muitas estrias e assimétrico, e 5. nota máxima - muito atraente: boa cor, sem estrias e simétrico); aparência da casca (1. nota mínima - casca muito grossa e esfarinhenta, e 5. nota máxima - casca nem muito fina e nem muito grossa, e não esfarinhenta); textura (1. nota mínima - nenhuma maciez, é preciso realizar muito esforço para morder e mastigar, e 5. nota máxima - muito macio, é preciso realizar pouco esforço para morder e mastigar); sabor (1. nota mínima - nenhum sabor de queijo ou sabor desagradável, e 5. nota máxima - muito sabor de queijo ou sabor agradável); avaliação global (1. produto pouco característico, e 5. produto completamente característico).

\section{Análise de textura}

Foi avaliada a força em compressão, expressa em grama-força (gf), utilizando Texturômetro TA-XT2i (probe cilíndrico de alumínio P36R; velocidade pré-teste $1,0 \mathrm{~mm} \cdot \mathrm{s}^{-1}$, velocidade teste $1,7 \mathrm{~mm} \cdot \mathrm{s}^{-1}$ e velocidade pós-teste 10,0 mm.s. $\mathrm{s}^{-1}$; distância 40,0\%; trigger 5,0 g) (STABLE MICRO SYSTEMS, 1997).

Para cada avaliação de textura, foram feitas seis réplicas (unidades).

\section{Volume específico}

O volume específico, expresso $\mathrm{em} \mathrm{cm}^{3} \cdot \mathrm{g}^{-1}$, foi calculado pela relação entre o volume de três unidades de pão de queijo $\left(\mathrm{cm}^{3}\right)$, determinado pelo método de deslocamento de sementes e o seu peso (g) (ZAMBRANO et al., 2009).

\section{Analise estatística}

Os resultados da avaliação sensorial (aparência, aparência da casca, textura, sabor e avaliação global), do volume específico e da textura instrumental das amostras de PQE e PQSE, com substituição de gordura, foram submetidos à análise de variância e ao teste de Tukey. Foi realizada comparação das amostras dentro de cada época (linha) e durante o período de estocagem (coluna) no nível de significância de 95\%, por meio do programa SAS (Statistical Analysis System, versão 8.0 - The SAS Institute, Cary, N.C.).

Foram realizadas comparações entre as médias em dois conjuntos de dados: o primeiro, com as amostras de PQE, e o segundo, com as de PQSE. Para cada tipo de processamento, foi utilizado um padrão (Tabela 1).

\section{Resultados e discussão}

Nas Tabelas 4 e 5, são apresentados os resultados da avaliação das características sensoriais de PQE e PQSE com substituição de gordura, respectivamente.

A substituição de $75 \%$ de gordura no PQE permitiu obter produtos com características sensoriais iguais às do padrão, quando estocados apenas durante um mês. No entanto, níveis de substituição de 25 e 50\% no PQE produziram melhores resultados. Nesses níveis, o PQE estocado por até três meses não apresentou diferença significativa $(p>0,05)$ nas características sensoriais com relação ao padrão.

Por outro lado, a substituição de gordura no PQSE permitiu obter produtos com 25, 50, 75 e $100 \%$ de substituição de gordura quando estocados durante três meses, com todas as características sensoriais avaliadas estatisticamente iguais $(p>0,05)$ ao padrão. 
Diversamente, o PQSE, estocado durante quatro meses, com $50 \%$ de substituição, apresentou diferença significativa $(p \leq 0,05)$ apenas na textura e na aparência da casca.

Os resultados do efeito da estocagem nas características sensoriais do pão de queijo foram diferentes entre PQE e PQSE. A estocagem não ocasionou diferença significativa $(p>0,05)$ nas características sensoriais do PQSE com até 100\% de substituição. Já a estocagem durante três meses do PQE, com 25\% de substituição de gordura, provocou diferença significativa na textura e na aparência da casca.

Houve maior variação nas características sensoriais no PQE, quando comparado com o PQSE. Esses resultados estão relacionados com a utilização de amido modificado na formulação do PQSE, com as características de cada um dos processos de fabricação utilizados e com as propriedades do CPS como substituto de gordura.

No PQSE, os grânulos de amido não são gelatinizados durante a mistura conforme acontece no processamento do PQE, sendo apenas utilizada temperatura acima daquela de gelatinização do amido de mandioca na etapa de assamento. Por isso, o amido modificado utilizado na elaboração do PQSE tem de ser pré-gelatinizado.
A função do amido pré-gelatinizado é ligar água a frio necessária para a formação da pressão de vapor de água, criando o efeito de expansão do pão de queijo durante o forneamento. Essa água ligada hidrata as proteínas do sistema, indispensáveis para o desenvolvimento da resistência da rede formada, prevenindo assim o colapso da estrutura do produto após o forneamento (SANTOS, 2006).

Além da pré-gelatinização, o amido de mandioca tem sido regularmente submetido a outras modificações, como a interligação, melhorando a resistência a: (i) ruptura mecânica durante a gelatinização; (ii) altas temperaturas; (iii) níveis baixos de pH (NABESHIMA e GROSSMANN, 2001), e (iv) retrogradação a baixas temperaturas em razão da presença de grupos fosfato.

Poucos trabalhos avaliaram o desempenho do amido de mandioca pré-gelatinizado na elaboração de PQSE em comparação com o PQE. Segundo Santos (2006), que avaliou o PQE e o PQSE no desenvolvimento de um produto funcional adicionado de polidextrose e concentrado proteico de soja, a utilização de amido modificado é adequada, pois reduz o tempo de preparação dos pães de queijo sem interferir na qualidade final do produto.

No PQSE, as células de ar incorporadas durante a mistura dos ingredientes se expandem por causa do

Tabela 4. Características sensoriais do PQE com substituição de gordura.

\begin{tabular}{|c|c|c|c|c|c|}
\hline \multirow{2}{*}{ Atributo } & \multirow{2}{*}{$\begin{array}{c}\text { Tempo } \\
\text { (meses) }\end{array}$} & \multicolumn{4}{|c|}{ Nível de substituição (\%) } \\
\hline & & $\mathbf{0}$ & 25 & 50 & 75 \\
\hline \multirow[t]{4}{*}{ Aparência } & 0 & $3,9 \pm 0,7^{\mathrm{aA}}$ & $3,7 \pm 0,7^{\mathrm{aA}}$ & $3,9 \pm 0,9^{a A}$ & $3,7 \pm 0,7^{\mathrm{aA}}$ \\
\hline & 1 & $3,8 \pm 1,1^{\mathrm{aA}}$ & $3,8 \pm 1,1^{\mathrm{aA}}$ & $3,8 \pm 1,4^{\mathrm{aA}}$ & $2,7 \pm 1,0^{\mathrm{aA}}$ \\
\hline & 2 & $3,7 \pm 0,8^{\mathrm{aA}}$ & $3,9 \pm 0,6^{\mathrm{aA}}$ & $4,0 \pm 0,7^{\mathrm{aA}}$ & $2,8 \pm 1,2^{\mathrm{bA}}$ \\
\hline & 3 & $3,8 \pm 0,8^{\mathrm{aA}}$ & $3,4 \pm 0,8^{\mathrm{aA}}$ & $3,8 \pm 0,6^{\mathrm{aA}}$ & $3,5 \pm 1,2^{\mathrm{aA}}$ \\
\hline \multirow[t]{4}{*}{ Aparência da casca } & 0 & $4,3 \pm 0,4^{\mathrm{aA}}$ & $4,5 \pm 0,5^{\mathrm{aA}}$ & $4,3 \pm 1,0^{\mathrm{aA}}$ & $3,3 \pm 0,9^{b A}$ \\
\hline & 1 & $3,7 \pm 0,8^{\mathrm{aA}}$ & $4,0 \pm 0,8^{\mathrm{aAB}}$ & $3,8 \pm 1,0^{\mathrm{aA}}$ & $3,1 \pm 1,4^{\mathrm{aA}}$ \\
\hline & 2 & $3,8 \pm 0,8^{\mathrm{abA}}$ & $4,1 \pm 1,0^{\mathrm{aAB}}$ & $4,2 \pm 0,9^{\mathrm{aA}}$ & $3,0 \pm 0,9^{b A}$ \\
\hline & 3 & $3,5 \pm 1,6^{\mathrm{aA}}$ & $2,8 \pm 1,2^{\mathrm{aB}}$ & $3,9 \pm 0,9^{a A}$ & $3,6 \pm 1,1^{\mathrm{aA}}$ \\
\hline \multirow[t]{4}{*}{ Textura } & 0 & $4,7 \pm 0,4^{\mathrm{aA}}$ & $4,3 \pm 0.8^{\mathrm{aA}}$ & $4,4 \pm 0.7^{\mathrm{aA}}$ & $3,9 \pm 0.8^{\mathrm{aA}}$ \\
\hline & 1 & $3,5 \pm 0,5^{\mathrm{aA}}$ & $3,8 \pm 0,6^{\mathrm{aAB}}$ & $4,3 \pm 0,8^{\mathrm{aA}}$ & $3,4 \pm 1,1^{\mathrm{aA}}$ \\
\hline & 2 & $3,9 \pm 0,9^{\mathrm{aA}}$ & $4,4 \pm 0,6^{\mathrm{aA}}$ & $3,8 \pm 1,1^{\mathrm{aA}}$ & $3,3 \pm 0,9^{a A}$ \\
\hline & 3 & $3,7 \pm 1,0^{\mathrm{aA}}$ & $2,8 \pm 1,0^{\mathrm{aB}}$ & $3,7 \pm 0,7^{\mathrm{aA}}$ & $3,5 \pm 1,1^{\mathrm{aA}}$ \\
\hline \multirow[t]{4}{*}{ Sabor } & 0 & $4,0 \pm 0,7^{\mathrm{aA}}$ & $4,1 \pm 0,7^{\mathrm{aA}}$ & $4,1 \pm 1,0^{\mathrm{aA}}$ & $3,7 \pm 1,0^{\mathrm{aA}}$ \\
\hline & 1 & $3,7 \pm 0,7^{\mathrm{aA}}$ & $3,9 \pm 0,7^{\mathrm{aA}}$ & $3,3 \pm 1,2^{\mathrm{aA}}$ & $3,4 \pm 1,2^{\mathrm{aA}}$ \\
\hline & 2 & $3,7 \pm 1,0^{\mathrm{aA}}$ & $4,0 \pm 1,0^{\mathrm{aA}}$ & $3,9 \pm 1,0^{\mathrm{aA}}$ & $3,3 \pm 1,0^{a A}$ \\
\hline & 3 & $2,9 \pm 1,2^{\mathrm{aA}}$ & $3,4 \pm 1,1^{\mathrm{aA}}$ & $2,9 \pm 0,7^{\mathrm{aA}}$ & $3,3 \pm 1,0^{a A}$ \\
\hline \multirow[t]{4}{*}{ Avaliação Global } & 0 & $4,3 \pm 0,4^{\mathrm{aA}}$ & $4,0 \pm 0,7^{a A}$ & $4,3 \pm 0,8^{a A}$ & $3,6 \pm 0,8^{a A}$ \\
\hline & 1 & $3,5 \pm 0,5^{\mathrm{aA}}$ & $3,8 \pm 0,6^{\mathrm{aA}}$ & $3,7 \pm 1,3^{\mathrm{aA}}$ & $3,1 \pm 0,9^{a A}$ \\
\hline & 2 & $3,7 \pm 0,7^{\mathrm{abA}}$ & $4,2 \pm 0,8^{a A}$ & $3,9 \pm 0,7^{\mathrm{abA}}$ & $3,2 \pm 0,8^{b A}$ \\
\hline & 3 & $3,2 \pm 1,0^{\mathrm{aA}}$ & $3,2 \pm 0,6^{a A}$ & $3,8 \pm 0,6^{a A}$ & $3,3 \pm 1,0^{a A}$ \\
\hline
\end{tabular}

Resultados expressos como média \pm desvio padrão. Em cada linha, médias seguidas de letras minúsculas iguais não diferem significativamente entre si pelo Teste de Tukey $(p>0,05)$. Em cada coluna, médias seguidas de letras maiúsculas iguais não diferem significativamente entre si pelo Teste de Tukey $(p>0,05)$. 
vapor de água liberado durante o assamento (PEREIRA, 1998). Já no PQE, a massa é aerada em função da incorporação de células de ar durante a mistura dos ingredientes e pelos lipídios, durante o escaldamento.

Foram encontrados na literatura poucos resultados de avaliação da substituição de gordura em pão de queijo, utilizando-se CPS. Clareto et al. (2006) avaliaram o efeito da substituição de gordura com o mesmo CPS avaliado neste trabalho, utilizando também uma escala de 1 a 5 ; no entanto, foram 12 provadores e a avaliação deu-se 15 min após assamento. Esses autores citaram resultados similares, como as notas da aparência que se incrementaram com o aumento do grau de substituição de gordura; no entanto, estas não apresentaram diferença significativa e todas as amostras apresentaram de média (3) a boa (4) aparência. De forma geral, o sabor de queijo não foi afetado pela adição de substituto e a crosta ficou mais grossa com o aumento do nível de adição de CPS. O pão de queijo com características mais adequadas segundo os provadores foi aquele com 10\% de substituição.
O Dairy-Lo é um substituto de gordura derivado de proteína de soro de leite, constituído por 35\% de proteína - sendo a beta-lactoglobulina no seu estado nativo a principal proteína -, 3,5\% de gordura, $52 \%$ de carboidratos e menos de $9 \%$ de fibra (CLARETO et al., 2006). Dentre as proteínas do soro de leite, a betalactoglobulina é a que apresenta melhores propriedades gelatinizantes (RATTRAY e JELEN, 1997).

Esse CPS tem a capacidade de formar um gel quando aquecido a temperaturas superiores a de desnaturação (YAZICI e AKGUN, 2004). A capacidade das proteínas do soro de leite, quando em solução, de formar géis estáveis por meio do aquecimento é uma importante propriedade funcional já conhecida. Com o aumento da concentração proteica, ocorre modificação da textura dos géis, resultando em aumento da firmeza e intensificando a retenção de água pela matriz (MANGINO, 1984).

Para o processo de gelatinização do CPS, é necessária uma concentração mínima de proteínas que, à temperatura na faixa de 70 a $90{ }^{\circ} \mathrm{C}$, pode variar entre 6 e 12\%, dependendo do $\mathrm{pH}$. Temperaturas

Tabela 5. Características sensoriais do PQSE com substituição de gordura.

\begin{tabular}{|c|c|c|c|c|c|c|}
\hline \multirow{2}{*}{ Atributo } & \multirow{2}{*}{$\begin{array}{c}\text { Tempo } \\
\text { (meses) }\end{array}$} & \multicolumn{5}{|c|}{ Nível de substituição (\%) } \\
\hline & & 0 & 25 & 50 & 75 & 100 \\
\hline \multirow[t]{5}{*}{ Aparência } & 0 & $4,4 \pm 0,9^{\mathrm{aA}}$ & $3,4 \pm 1,2^{\mathrm{aA}}$ & $3,3 \pm 0,8^{a A}$ & $3,5 \pm 0,9^{a A}$ & $3,4 \pm 0,7^{\mathrm{aA}}$ \\
\hline & 1 & $4,1 \pm 0,7^{\mathrm{aA}}$ & $4,3 \pm 0,6^{\mathrm{aA}}$ & $3,9 \pm 1,3^{\mathrm{aA}}$ & $4,1 \pm 0,7^{\mathrm{aA}}$ & $3,4 \pm 0,7^{\mathrm{aA}}$ \\
\hline & 2 & $4,3 \pm 0,4^{\mathrm{aA}}$ & $3,7 \pm 0,7^{\mathrm{aA}}$ & $3,2 \pm 1,3^{\mathrm{aA}}$ & $3,4 \pm 0,9^{a A}$ & $3,9 \pm 0,9^{a A}$ \\
\hline & 3 & $3,8 \pm 0,9^{\mathrm{aA}}$ & $3,6 \pm 0,7^{\mathrm{aA}}$ & $3,4 \pm 1,1^{\mathrm{aA}}$ & $3,3 \pm 1,2^{\mathrm{aA}}$ & $3,8 \pm 1,3^{\mathrm{aA}}$ \\
\hline & 4 & $3,6 \pm 0,6^{\mathrm{aA}}$ & $3,1 \pm 1,0^{\mathrm{aA}}$ & $3,0 \pm 0,6^{\mathrm{aA}}$ & $3,1 \pm 0,9^{\mathrm{aA}}$ & $3,2 \pm 0,8^{\mathrm{aA}}$ \\
\hline \multirow[t]{5}{*}{ Aparência da casca } & 0 & $4,1 \pm 1,0^{\mathrm{aA}}$ & $4,4 \pm 0,9^{\mathrm{aA}}$ & $3,8 \pm 1,0^{\mathrm{aA}}$ & $3,9 \pm 0,9^{a A}$ & $4,1 \pm 0,9^{a A}$ \\
\hline & 1 & $4,1 \pm 1,0^{\mathrm{aA}}$ & $4,2 \pm 0,8^{\mathrm{aA}}$ & $3,8 \pm 1,4^{\mathrm{aA}}$ & $4,0 \pm 1,1^{\mathrm{aA}}$ & $3,9 \pm 1,3^{\mathrm{aA}}$ \\
\hline & 2 & $4,3 \pm 0,6^{\mathrm{aA}}$ & $4,0 \pm 0,9^{a A}$ & $4,1 \pm 0,7^{\mathrm{aA}}$ & $3,9 \pm 0,9^{\mathrm{aA}}$ & $3,8 \pm 1,0^{\mathrm{aA}}$ \\
\hline & 3 & $4,2 \pm 0,9^{\mathrm{aA}}$ & $4,0 \pm 1,0^{\mathrm{aA}}$ & $3,8 \pm 1,3^{\mathrm{aA}}$ & $3,7 \pm 1,4^{\mathrm{aA}}$ & $3,4 \pm 1,1^{\mathrm{aA}}$ \\
\hline & 4 & $4,0 \pm 1,0^{\mathrm{aA}}$ & $4,0 \pm 0,9^{a A}$ & $2,7 \pm 1,1^{\mathrm{bA}}$ & $3,3 \pm 1,2^{\mathrm{abA}}$ & $3,8 \pm 1,0^{a A}$ \\
\hline \multirow[t]{5}{*}{ Textura } & 0 & $4,1 \pm 1,2^{\mathrm{aA}}$ & $4,0 \pm 1,0^{\mathrm{aA}}$ & $3,9 \pm 1,1^{\mathrm{aA}}$ & $3,7 \pm 0,9^{\mathrm{aA}}$ & $3,7 \pm 1,2^{\mathrm{aA}}$ \\
\hline & 1 & $3,8 \pm 1,0^{\mathrm{aA}}$ & $3,9 \pm 0,9^{a A}$ & $3,9 \pm 0,9^{a A}$ & $4,1 \pm 0,7^{\mathrm{aA}}$ & $3,7 \pm 0,9^{a A}$ \\
\hline & 2 & $4,4 \pm 0,7^{\mathrm{aA}}$ & $4,2 \pm 0,8^{\mathrm{aA}}$ & $4,2 \pm 0,8^{\mathrm{aA}}$ & $3,9 \pm 0,7^{\mathrm{aA}}$ & $3,8 \pm 1,0^{a A}$ \\
\hline & 3 & $4,4 \pm 0,7^{\mathrm{aA}}$ & $4,3 \pm 0,8^{\mathrm{aA}}$ & $4,1 \pm 1,0^{\mathrm{aA}}$ & $3,9 \pm 1,1^{\mathrm{aA}}$ & $4,0 \pm 0,6^{\mathrm{aA}}$ \\
\hline & 4 & $4,3 \pm 0,5^{\mathrm{aA}}$ & $4,0 \pm 0,9 \mathrm{abA}$ & $3,3 \pm 0,5^{\mathrm{bA}}$ & $3,7 \pm 1,0^{\mathrm{abA}}$ & $4,1 \pm 0,8^{\mathrm{aA}}$ \\
\hline \multirow[t]{5}{*}{ Sabor } & 0 & $4,0 \pm 0.7^{\mathrm{aA}}$ & $4,1 \pm 0.7^{\mathrm{aA}}$ & $3,3 \pm 0.9^{a A}$ & $3,6 \pm 1.1^{\mathrm{aA}}$ & $3,7 \pm 0,9^{a A}$ \\
\hline & 1 & $3,5 \pm 1.2^{\mathrm{aA}}$ & $3,7 \pm 1.0^{\mathrm{aA}}$ & $3,9 \pm 1.1^{\mathrm{aA}}$ & $4,0 \pm 0.9^{a A}$ & $4,1 \pm 1,0^{\mathrm{aA}}$ \\
\hline & 2 & $3,7 \pm 0.8^{\mathrm{aA}}$ & $3,8 \pm 0.9^{a A}$ & $3,6 \pm 0.8^{\mathrm{aA}}$ & $3,4 \pm 0.9^{\mathrm{aA}}$ & $3,8 \pm 1,0^{a A}$ \\
\hline & 3 & $3,5 \pm 1.2^{\mathrm{aA}}$ & $4,1 \pm 0.8^{\mathrm{aA}}$ & $3,6 \pm 1.1^{\text {aA }}$ & $3,7 \pm 1.0^{\mathrm{aA}}$ & $3,9 \pm 0,9^{a A}$ \\
\hline & 4 & $3,7 \pm 0.6^{\mathrm{aA}}$ & $3,5 \pm 0.9^{\mathrm{aA}}$ & $3,4 \pm 0.7^{\mathrm{aA}}$ & $3,3 \pm 0.9^{a A}$ & $3,3 \pm 1,0^{a A}$ \\
\hline \multirow[t]{5}{*}{ Avaliação global } & 0 & $4,2 \pm 0,7^{\mathrm{aA}}$ & $3,8 \pm 0,8^{\mathrm{aA}}$ & $3,6 \pm 0,8^{a A}$ & $3,7 \pm 0,9^{a A}$ & $3,7 \pm 1,0^{a A}$ \\
\hline & 1 & $3,6 \pm 1,1^{\mathrm{aA}}$ & $3,9 \pm 0,8^{\mathrm{aA}}$ & $3,9 \pm 1,1$ aA & $4,0 \pm 0,9^{a A}$ & $3,8 \pm 0,8^{a A}$ \\
\hline & 2 & $4,1 \pm 0,5^{\mathrm{aA}}$ & $3,8 \pm 0,6^{\mathrm{aA}}$ & $3,5 \pm 0,6^{a A}$ & $3,8 \pm 0,7^{\mathrm{aA}}$ & $3,8 \pm 0,8^{a A}$ \\
\hline & 3 & $4,0 \pm 0,8^{\mathrm{aA}}$ & $3,9 \pm 0,8^{\mathrm{aA}}$ & $3,7 \pm 0,8^{\mathrm{aA}}$ & $3,6 \pm 0,9^{a A}$ & $3,7 \pm 1,1^{\mathrm{aA}}$ \\
\hline & 4 & $3,6 \pm 0,7^{\mathrm{aA}}$ & $3,6 \pm 0,7^{\mathrm{aA}}$ & $3,1 \pm 0,7^{\mathrm{aA}}$ & $3,3 \pm 0,7^{\mathrm{aA}}$ & $3,6 \pm 0,7^{\mathrm{aA}}$ \\
\hline
\end{tabular}

Resultados expressos como média \pm desvio padrão. Em cada linha, médias seguidas de letras minúsculas iguais não diferem significativamente entre si pelo Teste de Tukey $(p>0,05)$. Em cada coluna, médias seguidas de letras maiúsculas iguais não diferem significativamente entre si pelo Teste de Tukey $(p>0,05)$. 
elevadas favorecem a formação de géis mais firmes (ANTUNES et al., 2003). Conforme já citado, durante o assamento, a temperatura no interior do pão de queijo atinge valores próximos a $75^{\circ} \mathrm{C}$.

Segundo Lucca e Tepper (1994), o Dairy-Lo é um derivado de proteína modificada obtida pela inativação térmica controlada do soro, tendo como resultado o desenovelamento da proteína; assim, ao expor regiões hidrofóbicas da cadeia polipeptídica, confere-se um caráter anfifílico, o que melhora, por sua vez, a capacidade de emulsificação. Já a autoagregação e o desenovelamento aumentam a interação da proteína com a água, melhorando a textura dos alimentos com baixo teor de gordura (CÂNDIDO, 1996). Segundo Sivieri e Oliveira (2002), essas propriedades dos CPS são melhoradas pela desnaturação térmica, permitindo-lhe atuar como substituto de gordura. O elemento comum nos sistemas de substituição de gordura é a água e o sucesso do CPS depende do controle dessa água, de forma a proporcionar funcionalidade da gordura que falta (CÂNDIDO e CAMPOS, 1995) e/ou foi substituída.

Nas Tabelas 6 e 7 são apresentados os resultados de volume específico e textura instrumental do PQE e PQSE com substituição de gordura, respectivamente.

A incorporação de CPS no PQSE não ocasionou diferença significativa no volume específico avaliado no tempo inicial e após um mês, quando comparado com o valor do pão de queijo padrão. Já o volume específico do PQE com 50\% de substituição de gordura diferiu significativamente do padrão nos períodos 1, 2 , e 3; no entanto, apresentou valores maiores que os do padrão em função das propriedades de formação de gel e emulsificação, que melhoraram o crescimento do pão de queijo durante o forneamento. Santos (2006) reportou resultados de volume específico e textura instrumental de PQE e PQSE adicionados de polidextrose e concentrado proteico de soja de 2,72 $\mathrm{cm}^{3} \cdot \mathrm{g}^{-1} / 1641,20 \mathrm{gf}$ e 2,67 $\mathrm{cm}^{3} \cdot \mathrm{g}^{-1} / 1917,40 \mathrm{gf}$, respectivamente. Já Pereira (2001), citado por Santos (2006), determinou um volume específico de $4,90 \mathrm{~cm}^{3} \cdot \mathrm{g}^{-1}$, enquanto Machado (2003), citado por Santos (2006), observou para esse mesmo parâmetro um valor de $3,68 \mathrm{~cm}^{3} \cdot \mathrm{g}^{-1}$ em PQE.

Os resultados reportados por esses autores se situam em faixas diferentes dos apresentados nas Tabelas 6 e 7 .

Das características avaliadas no PQE e PQSE, a aparência da casca e a textura instrumental (Tabelas 6 e 7) foram as mais prejudicadas e as que mais apresentaram diferença significativa com a substituição de gordura e a estocagem.

A gordura afeta a textura, o sabor e a aparência final do pão de queijo por atuar como emulsificante e lubrificante (MAISTRO, 1999). Segundo Canavesi et al. (1997), a gordura atua como um lubrificante molecular, ajudando a massa de pão de queijo a ter maior extensibilidade, contribuindo para maior elasticidade e melhor textura do miolo e melhor aspecto da crosta. Além disso, os lipídios da formulação do pão de queijo podem interagir com a amilose, deixando a textura do miolo mais macia, além de auxiliar a retenção de umidade e retardar o envelhecimento. A gordura retém bolhas de ar, formando uma estrutura semelhante à espuma, na qual se dará a cimentação do amido gelatinizado (PIROZI e CANAVESI, 1998), influenciando a estrutura/textura do pão de queijo. A gordura aquecida durante o escaldamento ajuda na transferência de calor, influenciando, por sua vez, na gelatinização do amido.

Apesar de os CPS oferecerem inúmeras e vantajosas propriedades, tais como solubilidade, emulsificação, gelatinização, retenção de água, viscosidade, cor, sabor, textura, formação de espuma e aeração, que lhes permite atuar como substitutos de gordura quando em concentrações de 34 a 85\% de proteína (ANTUNES et al., 2003), os CPS não apresentam todos os benefícios que a

Tabela 6. Volume específico e textura instrumental do PQE com substituição de gordura.

\begin{tabular}{|c|c|c|c|c|c|}
\hline & \multirow{2}{*}{$\begin{array}{c}\text { Tempo } \\
\text { (meses) }\end{array}$} & \multicolumn{4}{|c|}{ Nível de substituição (\%) } \\
\hline & & 0 & 25 & 50 & 75 \\
\hline \multirow{4}{*}{ 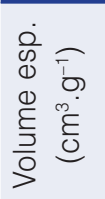 } & 0 & $39,80 \pm 0,67^{\mathrm{aA}}$ & $38,70 \pm 1,86^{a A}$ & $39,30 \pm 1,04^{\mathrm{AaB}}$ & $34,70 \pm 1,10^{\mathrm{bA}}$ \\
\hline & 1 & $36,70 \pm 1,72^{\mathrm{bB}}$ & $32,60 \pm 1,34^{\mathrm{CB}}$ & $40,90 \pm 1,88^{\mathrm{aAB}}$ & $33,20 \pm 2,28^{c A}$ \\
\hline & 2 & $32,40 \pm 1,19 \mathrm{bc}$ & $33,10 \pm 3,68^{\mathrm{bB}}$ & $42,40 \pm 3,83^{\mathrm{aA}}$ & $36,00 \pm 1,22^{\mathrm{bA}}$ \\
\hline & 3 & $32,70 \pm 1,92^{\mathrm{bC}}$ & $37,10 \pm 0,55^{\mathrm{aA}}$ & $37,80 \pm 1,15^{\mathrm{aB}}$ & $34,90 \pm 2,84^{\mathrm{abA}}$ \\
\hline \multirow{4}{*}{ 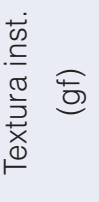 } & 0 & $1018,53 \pm 248,65^{\mathrm{aB}}$ & $1038,73 \pm 275,50^{\mathrm{aA}}$ & $734,35 \pm 158,60^{\mathrm{bBC}}$ & $1263,97 \pm 240,48^{\mathrm{aA}}$ \\
\hline & 1 & $1471,44 \pm 437,83^{\mathrm{aA}}$ & $1320,37 \pm 629,60^{\mathrm{abA}}$ & $837,71 \pm 139,63^{\mathrm{bB}}$ & $1636,59 \pm 481,92^{\mathrm{aA}}$ \\
\hline & 2 & $1575,53 \pm 282,57^{\text {aA }}$ & $1130,37 \pm 381,71^{\mathrm{bA}}$ & $1025,03 \pm 193,94^{\mathrm{bA}}$ & $1400,70 \pm 426,07^{\mathrm{abA}}$ \\
\hline & 3 & $1039,03 \pm 137,40^{\mathrm{bB}}$ & $1038,73 \pm 275,50^{\mathrm{bA}}$ & $609,04 \pm 47,81^{\mathrm{cc}}$ & $1609,26 \pm 43,31^{\mathrm{aA}}$ \\
\hline
\end{tabular}

Resultados expressos como média \pm desvio padrão. Em cada linha, médias seguidas de letras minúsculas iguais não diferem significativamente entre si pelo Teste de Tukey $(p>0,05)$. Em cada coluna, médias seguidas de letras maiúsculas iguais não diferem significativamente entre si pelo Teste de Tukey $(p>0,05)$. 
Tabela 7. Volume específico e textura instrumental do PQSE com substituição de gordura.

\begin{tabular}{|c|c|c|c|c|c|c|}
\hline \multirow{2}{*}{\multicolumn{2}{|c|}{$\begin{array}{c}\text { Tempo } \\
\text { (meses) }\end{array}$}} & \multicolumn{5}{|c|}{ Nível de substituição (\%) } \\
\hline & & 0 & 25 & 50 & 75 & 100 \\
\hline \multirow{2}{*}{ 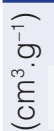 } & 0 & $43,60 \pm 2,07^{a B}$ & $43,0 \pm 1,84^{\mathrm{aA}}$ & $41,30 \pm 5,65^{\mathrm{aA}}$ & $37,90 \pm 1,24^{\mathrm{aA}}$ & $40,30 \pm 4,62^{a A}$ \\
\hline & 1 & $38,20 \pm 3,90^{\mathrm{AB}}$ & $38,00 \pm 1,90^{\mathrm{aBC}}$ & $41,00 \pm 2,92^{\mathrm{aA}}$ & $36,80 \pm 0,84^{\mathrm{aA}}$ & $43,20 \pm 5,78^{a A}$ \\
\hline \multirow{3}{*}{$\begin{array}{l}\dot{0} \\
0 \\
0 \\
0 \\
\frac{0}{5} \\
\frac{3}{0}\end{array}$} & 2 & $42,40 \pm 2,22^{\mathrm{abAB}}$ & $35,50 \pm 0,50^{c c}$ & $35,80 \pm 3,62^{\mathrm{cA}}$ & $37,90 \pm 3,47^{\mathrm{bc} A}$ & $46,80 \pm 2,97^{\mathrm{aA}}$ \\
\hline & 3 & $44,50 \pm 2,92^{\mathrm{aA}}$ & $41,20 \pm 2,08^{\mathrm{abAB}}$ & $37,20 \pm 1,10^{\mathrm{bcA}}$ & $36,50 \pm 1,70^{\mathrm{cA}}$ & $42,40 \pm 3,38^{\mathrm{aA}}$ \\
\hline & 4 & $43,30 \pm 3,77^{\mathrm{aAB}}$ & $37,90 \pm 1,95^{\mathrm{abBC}}$ & $41,50 \pm 3,16^{\mathrm{abA}}$ & $36,80 \pm 2,14^{\mathrm{bA}}$ & $43,40 \pm 4,72^{\mathrm{aA}}$ \\
\hline \multirow{5}{*}{ 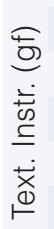 } & 0 & $1148,09 \pm 98,95^{a A}$ & $1021,20 \pm 227,04^{\mathrm{aAB}}$ & $1073,92 \pm 139,42^{\mathrm{aB}}$ & $1065,78 \pm 161,38^{\mathrm{aA}}$ & $1069,79 \pm 199,91^{\text {аАв }}$ \\
\hline & 1 & $849,98 \pm 90,29^{b c}$ & $789,93 \pm 134,89^{\mathrm{bBC}}$ & $1080,86 \pm 160,09^{a \mathrm{~B}}$ & $851,00 \pm 130,89 b c$ & $1020,37 \pm 135,05^{\mathrm{aAB}}$ \\
\hline & 2 & $831,80 \pm 116,64^{\mathrm{abc}}$ & $789,93 \pm 134,89^{\mathrm{bBC}}$ & $788,63 \pm 84,30^{\mathrm{bc}}$ & $904,55 \pm 140,78 \mathrm{abBC}$ & $941,79 \pm 49,57^{\mathrm{aBC}}$ \\
\hline & 3 & $1042,37 \pm 144,93^{\mathrm{abAB}}$ & $759,15 \pm 148,73^{c c}$ & $765,03 \pm 61,91^{\mathrm{cc}}$ & $950,58 \pm 97,64$ bABC & $1138,47 \pm 115,88^{\mathrm{aA}}$ \\
\hline & 4 & $951,37 \pm 160,13^{\mathrm{bcBC}}$ & $1153,25 \pm 241,72^{\mathrm{abA}}$ & $1342,78 \pm 191,10^{\mathrm{aA}}$ & $1034,54 \pm 76,03$ ьсАв & $902,43 \pm 97,97 \mathrm{cc}$ \\
\hline
\end{tabular}

Resultados expressos como média \pm desvio padrão. Em cada linha, médias seguidas de letras minúsculas iguais não diferem significativamente entre si pelo Teste de Tukey $(p>0,05)$. Em cada coluna, médias seguidas de letras maiúsculas iguais não diferem significativamente entre si pelo Teste de Tukey $(p>0,05)$.

gordura proporciona em termos de aparência da casca e textura na formulação de pão de queijo.

Além disso, as propriedades funcionais tecnológicas do CPS podem ser afetadas pelo alto teor de compostos não proteicos (PAGNO et al., 2009) e, conseqüentemente, a sua capacidade de substituir a gordura.

\section{Conclusões}

Os melhores níveis de substituição de gordura com CPS foram 50\% no PQE e 100\% no PQSE. Mesmo nesses níveis de substituição, houve diferenças significativas em função tanto da substituição da gordura por CPS como do tempo de estocagem do PQE e do PQSE.

Entre as duas variáveis estudadas, substituição de gordura e estocagem, essa última foi a que, de forma geral, menos influenciou nas características avaliadas dos pães de queijo.

\section{Agradecimentos}

Ao Conselho Nacional de Desenvolvimento Científico e Tecnológico - CNPq, pelo apoio por meio de Bolsa de Iniciação Científica.

\section{Referências}

ALMEIDA, K. E.; BONASSI, I. A.; ROÇA, R. O. Características físicas e químicas de bebidas lácteas fermentadas e preparadas com soro de queijo minas frescal. Ciência e Tecnologia de Alimentos, Campinas, v. 21, n. 2, p.187-192, 2001. http://dx.doi. org/10.1590/S0101-20612001000200012

ANTUNES, A. E. C.; CAZETO, T. F.; BOLINI, H. M. A. logurtes desnatados probióticos adicionados de concentrado protéico do soro de leite: perfil de textura, sinérese e análise sensorial. Alimentos e Nutrição, Araraquara, v. 15, n. 2, p. 107-114, 2004.
ANTUNeS, A. E. C.; MOTTA, E. M. P.; ANTUNES, A. J. Perfil de textura e capacidade de retenção de água de géis ácidos de concentrado protéico de soro de leite. Ciência e Tecnologia de Alimentos, Campinas, v. 23, p. 183-189, 2003. http://dx. doi. org/10.1590/S0101-20612003000400034

BENASSI, V. T.; WATANABE, E.; LOBO, A. R.; Produtos de panificação com conteúdo calórico reduzido. Boletim do Centro de Pesquisa e Processamento de Alimentos, Curitiba, v. 19, n. 2, p. 225-242, 2001.

CANAVESI, E.; PIROZI, M. R.; MACHADO, P. T.; MINIM, V. P. R. Efeito da concentração dos ingredientes nas características físico-químicas do pão de queijo. In: SIMPÓsIO LATINO AMERICANO DE CIÊNCIA DE ALIMENTOS, 2., 1997, Campinas. Resumos... Campinas: Editora UNICAMP, 1997

CÂNDIDO, L. M. B. Alimentos para Fins Especiais: Dietéticos. 2. ed. São Paulo: Varela, 1996. 424 p.

CÂNDIDO, L. M. B.; CAMPOS, A. M. Substitutos de gorduras. Boletim do Centro de Pesquisa e Processamento de Alimentos, Curitiba, v. 13, n. 2, p. 125-164, 1995.

CLARETO, S. S.; LEE, N .D. ; PEREIRA, A. J. G. Influence of a protein concentrate used as a fat substitute on the quality of cheese bread. Brazilian Archives of Biology and Technology, Curitiba, v. 49, n. 6, p. 478-484, 2006. http://dx.doi.org/10.1590/ S1516-89132006000700020

CONDACK, J. Ultrafiltração do Soro de Queijo: Parâmetros Operacionais e Utilização do Concentrado Protéico na Fabricação de Requeijão Cremoso. 1992. 117 f . Dissertação (Mestrado)-Universidade Federal de Viçosa, Viçosa, 1992.

ESTELLER, M. S.; LANNES, S. C. S. Parâmetros Complementares para fixação de identidade e qualidade de produtos panificados. Ciência e Tecnologia de Alimentos, Campinas, v. 25, n. 4, p. 802-806, 2005. http://dx.doi.org/10.1590/S010120612005000400028 
Concentrado protéico de soro como substituto de gordura em pão de queijo

ZAMBRANO, F. et al.

GIRALDO-ZUNIGA, A. D.; COIMBRA, J. S. R.; GOMES, J. C.; MINIM, L. A.; GARCIA, R. E. E. Propriedades funcionais e nutricionais das proteínas do soro de leite. Revista do Instituto de Laticínios Cândido Tostes, Juiz de Fora, v. 57, n. 325, p. 35-46, 2002.

INTERNATIONAL ORGANIZATION FOR STANDARDIZATION. ISO 8565-1: Sensory Analysis - General Guidance for Selection, Training and Monitoring of Assessors. Geneva: International Organization for Standardization, p.1-15,1993. Part 1: Selected assessors.

LUCCA, P. A.; TEPPER, B. J. Fat replacers and the functionality of fat in foods. Trends in Foods Science Technology, Cambridge, v. 5, n. 1, p. 12-19, 1994. http://dx.doi.org/10.1016/09242244(94)90043-4

MAISTRO, L. C. Aplicação de Concentrados Protéicos de Soro de Leite Bovino em logurtes. 1999. 107 f. Tese (Doutorado em Ciências da Nutrição)-Faculdade de Engenharia de Alimentos, Universidade Estadual de Campinas, Campinas, 1999.

MANGINO, M. E. Physicochemical aspects of whey protein functionality. Journal of Dairy Science, v. 67, n. 11, p. 2711-2722, 1984. http://dx.doi.org/10.3168/jds.S00220302(84)81629-X

McMAHON, D. J.; ALLEYNE, M. C.; FIFE, R. L.; OBER, C. J. Use of fat replacers in low fat mozzarella cheese. Journal of Dairy Science, Champaign, v. 79, n. 11, p. 1911-1921, 1996. http:// dx.doi.org/10.3168/jds.S0022-0302(96)76560-8

NABESHIMA, E. H.; GROSSMANN, M. V. E. Functional properties of pregelatinized and croo-linked cassava starch obtained by extrusion with sodium trimetaphosphate. Carbohydrates Polymers, Oxford, v. 45, n. 4, p. 347-353. 2001. http://dx.doi. org/10.1016/S0144-8617(00)00273-3

NEVES, B. S. Aproveitamento de subprodutos da indústria de laticínios. In: EMBRAPA GADO DE LEITE. Sustentabilidade da Pecuária de leite no Brasil: Qualidade e Segurança Alimentar. Juiz de Fora: Embrapa, 2001. p. 97-108.

O'BRIEN, C. M.; MUELLER, A.; SCANNELL, A. G. M.; ARENDT, $E$. $K$, Evaluation of the effects of fat replacers on the quality of wheat bread. Journal of Food Engineering, Oxford, v. 56, n. 2-3, p. 265-267, 2003. http://dx.doi.org/10.1016/S02608774(02)00266-2

PACHECO, M. T. B.; DIAS, N. F. G. ; BALDINI, V. L. S. ; TANIKAWA, C.; SGARBIERI, V. C. Propriedades funcionais de hidrolisados obtidos a partir de concentrados protéicos de soro de leite. Ciência e Tecnologia de Alimentos, Campinas, v. 25, n. 2, p. 333-338, 2005. http://dx.doi.org/10.1590/S010120612005000200026

PAGNO, C. H.; BALDASSO, C.; TESSARO, I. C.; FLORES, S. H.; JONH, E. V. Obtenção de concentrados protéicos de soro de leite e caracterização de suas propriedades funcionais tecnológicas. Alimentos e Nutrição, Araraquara, v. 20, n. 2 , p. 231-239, 2009.

PASCAL, G. Les substituts de matiéres grasses. Cahiers de Nutrition et de Dietetique, Paris, v. 27, n. 3, p. 179-184, 1992.

PEREIRA, A. J. G. Fatores que Afetam a Qualidade do Pão de Queijo. Belo Horizonte: CETEC, 1998. 52 p.

PEREIRA, J.; CIACCO, C. F; VILELA, E. R.; PEREIRA, R. G. F. A. Função dos ingredientes na consistência da massa e nas características do pão de queijo. Ciência e Tecnologia de Alimentos, Campinas, v. 24, n. 4, p. 494-550, 2004. http://dx.doi. org/10.1590/S0101-20612004000400003

PIROZI, M. R.; CANAVESI, E. Como Montar uma Pequena Fábrica de Pão de Queijo. Viçosa: CPT, 1998. 42 p.

RATTRAY, W.; JELEN, P. Thermal stability of skim milk/whey protein solution blends. Food Research International, v. 30, n. 5, p. 327-334, 1997. http://dx.doi.org/10.1016/S09639969(97)00056-2

SANDOVAL-CASTILLA, O.; LOBATO-CALLEROS, C.; AGUIRREMANDUJANO, E.; VERNON-CARTER, E. J. Microstructure and texture of yogurt as influenced by fat replacers. International Dairy Journal, Oxford, v. 14, n. 2, p. 151-159, 2004. http://dx. doi. org/10.1016/S0958-6946(03)00166-3

SANTOS, J. R. U. Desenvolvimento de Pão de Queijo Funcional pela Incorporação de Isolado Protéico de Soja e Polidextrose. 2006. 107 f. Tese (Mestre em tecnologia de Alimentos)-Faculdade de Engenharia de Alimentos, Universidade Estadual de Campinas, Campinas, 2006.

SIVIERI, K.; OLIVEIRA, M. N. Avaliação da vida-de-prateleira de bebidas lácteas preparadas com "fat replacers" (Litesse e Dairy-Lo). Ciência e Tecnologia de Alimentos, Campinas, v. 22, n. 1, 2002. Disponível em: <http://www.scielo.br/scielo. php?script=sci_arttext\&pid=S010120612002000100005>. Acesso em: 30 nov. 2010.

STABLE MICRO SYSTEMS. User Manual. version 6.10, 7.10. Vienna Court: Stable Micro Systems, 1997.87 p. Texture Analyser modelo TA-XT2i.

YAZICI, F.; AKGUN, A. Effect of some protein based fat replacers on physical, chemical, textural, and sensory properties of strained yoghurt. Journal of Food Engineering, Oxford, v. 62, n. 3, p. 245-254, 2004. http://dx.doi.org/10.1016/S02608774(03)00237-1

ZAMBRANO, F.; SILVA, M. C.; ORMENESE, R. C. S. C. Avaliação preliminar da utilização de concentrado protéico de soro como substituto de gordura e queijo em pão de queijo. In: SIMPÓSIO LATINO AMERICANO DE CIÊNCIA E TECNOLOGIA DE ALIMENTOS - SLACA, 8., 2009, Campinas. Anais... Campinas: Universidade Estadual de Campinas, 2009. 